\title{
Thoughts on Higher Medical Education under Major Public Health Emergencies: Thinking Ahead after COVID-19 Outbreak--A Descriptive Study
}

\author{
Wei Lin ${ }^{1}$, Yan Chen ${ }^{2}$, Songchang Shi ${ }^{3}$, Jixing Liang ${ }^{1}$, Huibin Huang ${ }^{1}$, Liantao Li $^{1}$, Liangchun Cai ${ }^{1}$, Liyao Zong ${ }^{1}$, Nengying Wang ${ }^{1}$, \\ Junping Wen ${ }^{1, *}$, and Gang Chen ${ }^{1,4, *}$
}

${ }^{1}$ Department of Endocrinology, Fujian Provincial Hospital, Shengli Clinical Medical College of Fujian Medical University, Fuzhou, China ${ }^{2}$ Office of Academic Research, Fujian Provincial Hospital, Fujian, China

${ }^{3}$ Department of Critical Care Medicine, Fujian Provincial Hospital South Branch, Shengli Clinical Medical College of Fujian Medical University, Fuzhou, China

${ }^{4}$ Fujian Academy of Medical Sciences, Fuzhou, Fujian, China

*Corresponding authors: Junping Wen, Professor, Fujian, Department of Endocrinology, Fujian Provincial Hospital, Shengli Clinical Medical College of Fujian Medical University, Fuzhou, China, E-mail: chengangfj@163.com

Gang Chen, Professor, Fujian Academy of Medical Sciences, Fuzhou, Fujian, China, E-mail: junpingwen@163.com

Received: 08 Mar, 2021 | Accepted: 24 Mar, 2021 | Published: 31 Mar, 2021

Citation: Lin W, Chen Y, Shi S, Liang J, Huang H, et al. (2021) Thoughts on Higher Medical Education under Major Public Health Emergencies: Thinking Ahead after COVID-19 Outbreak--A Descriptive Study. J Epidemiol Public Health Rev 6(1): dx.doi.org/10.16966/2471-8211.210

Copyright: (c) 2021 Lin W, et al. This is an open-access article distributed under the terms of the Creative Commons Attribution License, which permits unrestricted use, distribution, and reproduction in any medium, provided the original author and source are credited.

\section{Key Points}

Questions: What are the reflections on approaches to teaching and learning during COVID-19 Outbreak?

Findings: Fifty, $4^{\text {th }}$-year medical students receiving the " $5+3^{\text {" }}$ pattern courses regarding internal medicine were enrolled. Five-Point Likert Scale Questionnaires that contain 20 items were used. This study indicates that medical education based on $5 \mathrm{G}$ network that combined Team-Based Learning (TBL) and online interaction can be an effective option to teach medical students online during COVID-19 outbreak.

Meaning: China's experience in online higher medical education may serve as a reference to other countries during the pandemic.

\section{Abstract}

Background: The spread of coronavirus disease 2019 (COVID-19) has posed great threat to the global population's health and nearly every medical school throughout the world suspended classes as a precaution against the virus. This study is aimed at exploring a more advanced online teaching and learning pattern for medical school in the future especially during a Public Health Emergency of International Concern (PHEIC) and to evaluate the efficacy of the teaching methods in improving students' professionalism, knowledge and learning skills including problem analyzing and solving, teamwork skills, self-directed learning, as well as adaptability and acceptance to the courses.

Methods: Fifty, $4^{\text {th }}$-year medical students receiving the " $5+3$ " pattern courses regarding internal medicine were enrolled in the study. A five-point Likert scale questionnaire that contains 20 items was used to compare the effect between online TBL via 5 G network (hereinafter referred as blended teaching model) and home-based online learning which is not based on TBL via other prevalent forms of wireless internet connection(hereinafter referred as traditional online teaching model). It evaluated the network environment and indices of students' competencies we put forward based on six core competencies.

Results: According to the descriptive statistical analysis of the first part of the questionnaire (question 1-16), the average score of adaptability and acceptance of the courses is 2.60 less than 3 , indicating that students are more adapted to traditional online teaching model; the average score of the rest of the questions is greater than 3 , indicating that blended teaching model is superior to traditional online teaching model. The number of male students who are inclined to blended teaching model is 0.13 times as much as that of female students $\left(95 \% \mathrm{Cl}: 0.028^{\sim} 0.602, p=0.009\right)$.

Conclusion: Online TBL via $5 \mathrm{G}$ network is a more advanced online teaching and learning pattern for medical school and may be a more suitable method during PHEIC in the future.

Keywords: COVID-19; Medical education; Online; TBL; 5G; Pandemic

List of Abbreviations: COVID-19: Coronavirus disease 2019; TBL: Team-Based Learning; PHEIC: Public Health Emergency of International Concern; eMBB: Enhanced Mobile Broadband; mMTC: Massive Machine Type Communications; URLLC: Ultra-Reliable and Low Latency Communications; MOOCs: Massive Open Online Courses 


\section{Background}

Coronavirus Disease 2019 (COVID-19) has been ongoing in China since December 2019. On January 30, 2020, the second meeting of the Emergency Committee convened by the WHO Director-General under the International Health Regulations (IHR) declared that the outbreak of COVID-19 constitutes a Public Health Emergency of International Concern (PHEIC) [1]. The pandemic raised great concern in China and other countries [2-5]. In order to prevent the spread of COVID-19 at mass gatherings, Ministry of Education of the People's Republic of China adopted counter measures such as online education to keep medical schools running without suspending classes.

Before the COVID-19 pandemic, China's higher medical education mostly adopted traditional education model, namely the secondgeneration education model. However, with the incredible growth of Internet since the 1990s, online education has begun to thrive. In 2009, Khan Academy and flipped class became popular in China, and a number of higher medical education institutions in China have begun to accept or try online education. In 2010, large-scale online courses such as MOOCs had a tremendous impact on China's higher medical education. At present, there are numerous online platforms of MOOCs, including Coursera, Udacity and edX, the top three worldrenowned education platforms as well as domestic platforms such as Chinese university MOOC, Xuetang X and I courses. The proliferation of online education has already been an inevitable trend, and the COVID-19 pandemic facilitates this transformation.

Health professionals for a new century: transforming education to strengthen health systems in an interdependent world published in Lancet proposed an idea of the third-generation educational reform [6]. It focuses on system-based medical education to improve the performance of health systems by adapting core professional competencies to specific contexts, while drawing on global knowledge. With the rapid development of medical science, the traditional teaching methods featuring slow knowledge updating and low teaching efficiency, to some extent, are unable to fully meet the diverse learning needs of medical students. Proposed in 2003, blended learning has become one of the mainstream educational approaches in the medical educational reform [7]. It is a style of education in which students learn via electronic and online media as well as traditional face-toface teaching, that places an emphasis on empowering students with the skills and knowledge required to make the most of the online material and independent study time, guiding students toward the most meaningful experience possible [8]. E-learning is based on network support. $5 \mathrm{G}$ is the abbreviation of the fifth-generation mobile communication technology. 5G network features enhanced mobile broadband (eMBB) coping with the significant increase of data volumes, overall data capacity, and user density, massive machine type communications (mMTC) requiring low power consumption for a huge number of connected devices, ultra-reliable and low latency communications (URLLC) providing safety-critical and mission critical applications. Compared with $4 \mathrm{G}$ network, WLANs or Wi-Fi, $5 \mathrm{G}$ network guarantees the same consistency in performance with less interference that is very important for critical machine-to-machine communications, especially where the number of devices is massive.

Team-based learning (TBL) is a structured form of smallgroup learning that can be scaled up for implementation in large classes. Compared with problem-based learning, it is distinct in its requirement for pre-class preparation, its sequence of in-class individual and team activities, its higher student-teacher ratio, and the way it combines peer learning with immediate feedback and expert clarification [9]. " $5+3$ " pattern is an innovative training pattern in graduate education for a professional degree in clinical medicine [10]. The pattern focuses on innovation in training talent as well as reform of the administrative mechanism. In " $5+3$ " pattern, medical students directly enter the 3 years of pursuing a master's degree after completing 5 years of preclinical and clinical courses. It narrows the gap between student cultivation and standardized training for residents, facilitates the tight connection between professional training and occupational qualifications. In accordance with boosting medical educational reform by new technologies, we had tried to apply a new blended teaching model based on online TBL via $5 \mathrm{G}$ network (hereinafter referred as blended teaching model) to 50 fourth-year medical students who were receiving the " $5+3$ " pattern courses regarding internal medicine in July, 2019 before the outbreak of COVID-19. As the pandemic was later determined to be PHEIC, medical universities in China closed campuses and shifted to home-based online learning which is not based on TBL via other prevalent forms of wireless internet connection (hereinafter referred as traditional online teaching model) in response to the COVID-19 outbreak. It seems to be another alternative learning approach under PHEIC that conform to the trend of the third-generation educational reform.

In order to find a more suitable method to conduct medical education under PHEIC, we used an online survey tool to make a comparison between the blended teaching mode and the traditional online teaching model. In addition, we tried to discuss the impact of this change will bring towards the indices of students' competencies we put forward based on six core competencies, that is, professionalism, attitude towards learning, knowledge and learning skills including problem analyzing and solving, teamwork skills, self-directed learning, as well as adaptability and acceptance of the courses.

\section{Methods}

\section{Aim, design and setting}

Aim: The aim of this research is to explore a more advanced online teaching and learning pattern for medical school in the future especially during a Public Health Emergency of International Concern (PHEIC) and to evaluate the efficacy of the teaching methods in improving students' professionalism, knowledge and learning skills including problem analyzing and solving, teamwork skills, selfdirected learning, as well as adaptability and acceptance to the courses.

Study design: Fifty, $4^{\text {th }}$-year medical students receiving the " $5+3$ " pattern courses regarding internal medicine in Shengli Clinical Medical College of Fujian Medical University were enrolled in the study. All of the students attended the blended teaching model in 2019. They were allocated to 5 teams of 10 students each who work together throughout the whole process of the class and TBL was adopted in this model. Before class, daily learning tasks and materials was published at a fixed time through chat applications such as WeChat or QQ; an excellent student was designated as an assistant to be responsible for notifying other students of study tasks and urgent messages, and collecting questions raised by students. Through flipped classroom, students studied the pre-class materials on their own and prepared to give a presentation in the class. During the class, one of the students will represent their group to give a presentation and other groups comment on that presentation and address some questions. The teacher can facilitate an online class-wide discussion via the platform, and a question-and-answer round was arranged to allow multiple students to use tablets or mobile phones to discuss with the teacher simultaneously or ask the questions and expect a timely answer. After class, students do summary and reflection by group, and hand in the homework via the online platform. After the outbreak of COVID-19, 
they shifted to attend home-based online course which was not based on TBL via other prevalent forms of wireless internet connection. In order to compare the effectiveness between the two teaching methods, we designed a five-point bipolar Likert scale questionnaire in the electronic form and distributed it to the students via WeChat. They filled it out voluntarily and submitted the statistics the next day. The content of the questionnaire was referred to some domestic and foreign literature such as Health professionals for a new century: transforming education to strengthen health systems in an interdependent world published in 2010 [6].

The five-point bipolar Likert scale questionnaire regarding the two kinds of teaching patterns that contains 20 items was used to compare the two teaching models. It consists of 5 options that contain two extreme poles and a neutral option connected with intermediate answer options. The questionnaire was divided into two parts. The first part refers to the comparison between the effects of two kinds of teaching patterns. The options start with "strongly in favor of traditional online teaching model" at 1 point, "neutral" at 3 point, and "strongly in favor of blended teaching model" at 5 . The second part refers to the comparison between the user experience of online platform based on $5 \mathrm{G}$ network and other prevalent forms of wireless internet connection such as WIFI and $4 \mathrm{G}$ network. The options start with "strongly in favor of the user experience of other prevalent forms of wireless internet connection such as WIFI and $4 \mathrm{G}$ network" at 1 point, "neutral" at 3 point, and "strongly in favor of the user experience of online platform based on $5 \mathrm{G}$ network" at 5 .

The questionnaire in this study consists of two parts involving five aspects of indicators of learning efficacy (Figure 1). The first part of the questionnaire is designed on the basis of competency-oriented teaching. The items cover four indicators of students' competencies including A: professionalism and attitude towards learning (question 1-5), B: knowledge and learning skills (question 8,9,10,12,16), C: teamwork spirit (question 11), as well as D: motivation in learning and acceptance of the courses (question 6,7,13,14,15). The second part of questionnaire is mainly for the evaluation of network environment of online education including E: user experience under the certain network environment (question 17-20).

Setting: The study was conducted in an institute in Fujian Province in China, which can offer 5G network environments. The study protocol was approved by the Ethics Committee of Fujian Provincial Hospital (No. K2020-04-41), and all the participants provided written informed consent.

\section{Statistical analysis}

All data were collected by WJX, an electronic questionnaire design tool. They were verified by two teachers and exported to SPSS version 26.0 (IBM, United States). Reliability analysis and descriptive statistical analysis was conducted on the data, respectively. If data were normally distributed, they were expressed as mean \pm standard deviation. If data were not normally distributed, they were expressed as the median. In addition, the binary logistic regression was used to analyze the impact of gender on the scores of the questionnaire.

\section{Result}

\section{Basic information of the subjects}

As 50 fourth-year medical students receiving the " $5+3$ " pattern courses regarding internal medicine were enrolled in the study, 50 electronic questionnaires were distributed. Two students did not answer the questionnaire on time. Thus, only $96 \%(48 / 50)$ of the valid questionnaires were returned. The subjects aged $(22.4 \pm 0.79)$ years

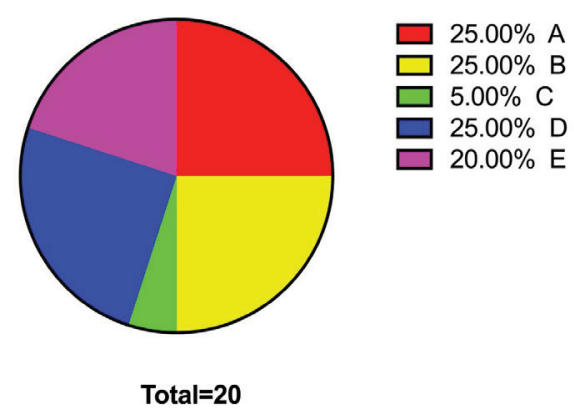

A:Professionalis and atitude towards learning (Question 1-5) B:Knowledge and learning skills (Question 8,9,10,12,16)

C:Teamwork spirit (Question 11)

D:Motivation in learning and acceptance of the courses (Question 6,7,13,14,15)

E:User experience under the certain network environment (Question 17-20)

Figure 1: The composition of indicators of learning efficacy in the questionnaire.

old, of which 25 were male students, accounting for $52.0 \%$ of the effective sample; 23 were female students, accounting for $48.0 \%$ of the effective sample.

\section{Data analysis}

Reliability analysis: Cronbach's Alpha in SPSS Statistics was used to measure the internal consistency of the valid questionnaires in this study. The results showed that the questionnaire has high internal consistency or high reliability as the value of Cronbach's Alpha is 0.73 , and the value of Cronbach's Alpha based on the standardized items is 0.95 , both of which are at a high level.

Descriptive statistical analysis: The data of the results of the questionnaire were normally distributed $(\mathrm{P}>0.05)$. Scores $1,2,3,4,5$ represented for strongly in favor of traditional online teaching model, in favor of traditional online teaching model, neutral, in favor of blended teaching model and strongly in favor of blended teaching model, respectively. The average scores were written in Mean \pm SD.

According to the descriptive statistical analysis of the first part of the questionnaire (question 1-16) (Table 1), the average score of adaptability and acceptance of the courses is 2.60 lower than 3 , indicating that students are more adapted to the traditional online teaching model during COVID-19 outbreak; the average score of the rest of the questions is higher than 3, indicating that the blended teaching model is much higher rated by the students on the aspects of professionalism, attitude towards learning, knowledge and learning skills, teamwork skills and motivation in learning (see Table 1); the average score of the challenging level of the course is 4.04 , indicating that the blended teaching model seemed to be more challenging for most of the students than the traditional online teaching model. According to the descriptive statistical analysis of the second part of the questionnaire (question 17-20) (Table 2), the average score of network latency and stability is 2.83 lower than 3 , which suggests that other forms of wireless internet connection were rated to be more stable currently; the rest of the questions in the second part of the questionnaire score greater than 3, indicating that students believe that the blended teaching model is better than the traditional online teaching model on the aspects of real-time interaction, high-definition image quality and voice clarity. 
Table 1: Descriptive statistical analysis of the first part of the questionnaire (question 1-16).

\begin{tabular}{|c|c|c|c|c|c|c|}
\hline Contents \scores & $\begin{array}{l}\mathbf{1} \text { (strongly in favor } \\
\text { of traditional online } \\
\text { teaching model) }\end{array}$ & $\begin{array}{c}2 \text { (in favor of } \\
\text { traditional online } \\
\text { teaching model) }\end{array}$ & 3(Neutral) & $\begin{array}{c}\text { 4(in favor of } \\
\text { blended teaching } \\
\text { model) }\end{array}$ & $\begin{array}{c}5 \text { (strongly in } \\
\text { favor of blended } \\
\text { teaching model) }\end{array}$ & $\begin{array}{c}\text { Score } \\
(\text { Mean } \pm \text { SD) }\end{array}$ \\
\hline (1)Expectations on the course & $10(20.8 \%)$ & $4(8.3 \%)$ & $15(31.3 \%)$ & $7(14.6 \%)$ & $12(25.0 \%)$ & $3.15 \pm 1.44$ \\
\hline (2)Satisfaction of the course & $7(14.6 \%)$ & $6(12.5 \%)$ & $17(35.4 \%)$ & $9(18.8 \%)$ & $9(18.18 \%)$ & $3.15 \pm 1.29$ \\
\hline (3)Innovation of the course & $6(12.5 \%)$ & $2(4.2 \%)$ & $8(16.7 \%)$ & $10(20.8 \%)$ & $22(45.8 \%)$ & $3.83 \pm 1.39$ \\
\hline (4)Course adaptability & $14(29.2 \%)$ & $7(14.6 \%)$ & $16(33.3 \%)$ & $6(12.5 \%)$ & $5(10.4 \%)$ & $2.60 \pm 1.31$ \\
\hline (5)Interaction of the course & $5(10.4 \%)$ & $2(4.2 \%)$ & $13(27.1 \%)$ & $12(25 \%)$ & $16(33.3 \%)$ & $3.67 \pm 1.28$ \\
\hline (6)Challenge of the course & $4(8.3 \%)$ & $1(2.1 \%)$ & $6(12.5 \%)$ & $15(31.3 \%)$ & $22(45.8 \%)$ & $4.04 \pm 1.20$ \\
\hline (7)Straight forwardness & $7(14.6 \%)$ & $4(8.3 \%)$ & $15(31.3 \%)$ & $11(22.9 \%)$ & $11(22.9 \%)$ & $3.31 \pm 1.32$ \\
\hline $\begin{array}{l}\text { (8)Improvement of preview } \\
\text { ability }\end{array}$ & $5(10.4 \%)$ & $2(4.2 \%)$ & $10(20.8 \%)$ & $14(29.2 \%)$ & $17(35.4 \%)$ & $3.75 \pm 1.28$ \\
\hline $\begin{array}{l}\text { (9)Improvement of ability of } \\
\text { independent learning }\end{array}$ & $6(12.5 \%)$ & $1(2.1 \%)$ & $12(25.0 \%)$ & $13(27.1 \%)$ & $16(33.3 \%)$ & $3.67 \pm 1.31$ \\
\hline $\begin{array}{l}\text { (10)Improvement of } \\
\text { comprehensive ability and } \\
\text { advanced thinking }\end{array}$ & $5(10.4 \%)$ & $0(0 \%)$ & $10(20.8 \%)$ & $17(35.4 \%)$ & $16(33.3 \%)$ & $3.81 \pm 1.20$ \\
\hline $\begin{array}{l}\text { (11)Cultivation of teamwork } \\
\text { spirit }\end{array}$ & $5(10.4 \%)$ & $0(0 \%)$ & $14(29.2 \%)$ & $14(29.2 \%)$ & $20(41.7 \%)$ & $3.92 \pm 1.25$ \\
\hline $\begin{array}{l}\text { (12)Improvement of problem } \\
\text { analyzing and solving abilities }\end{array}$ & $6(12.5 \%)$ & $0(0 \%)$ & $11(22.9 \%)$ & $17(35.4 \%)$ & $14(29.2 \%)$ & $3.69 \pm 1.26$ \\
\hline $\begin{array}{l}\text { (13)Teaching quality of the } \\
\text { course }\end{array}$ & $8(16.7 \%)$ & $2(4.2 \%)$ & $17(35.4 \%)$ & $14(29.2 \%)$ & $7(14.6 \%)$ & $3.21 \pm 1.25$ \\
\hline (14)Preference of the course & $10(20.8 \%)$ & $5(10.4 \%)$ & $16(33.3 \%)$ & $6(12.5 \%)$ & $11(22.9 \%)$ & $3.06 \pm 1.42$ \\
\hline $\begin{array}{l}\text { (15)Which form would you } \\
\text { prefer to spend more time on? }\end{array}$ & $9(18.8 \%)$ & $4(8.3 \%)$ & $13(27.1 \%)$ & $8(16.7 \%)$ & $14(29.2 \%)$ & $3.29 \pm 1.32$ \\
\hline $\begin{array}{l}\text { (16)Which form did you actually } \\
\text { spend more time on? }\end{array}$ & $8(16.7 \%)$ & $6(12.5 \%)$ & $13(27.1 \%)$ & $4(8.3 \%)$ & $17(35.4 \%)$ & $3.33 \pm 1.49$ \\
\hline
\end{tabular}

The first part of the questionnaire consists of 5 answer options which contain two extreme poles and a neutral option connected with intermediate answer options. It refers to the comparison between the effects of two kinds of teaching patterns. The options start with "strongly in favor of traditional online teaching model" at 1 point, "neutral" at 3 point, and "strongly in favor of blended teaching model" at 5.

Table 2: Descriptive statistical analysis of the second part of the questionnaire (question 17-20).

\begin{tabular}{|c|c|c|c|c|c|c|}
\hline Items\points & $\begin{array}{l}1 \text { (strongly in favor of } \\
\text { the user experience of } \\
\text { other prevalent forms } \\
\text { of wireless internet } \\
\text { connection such as WIFI } \\
\text { and } 4 \mathrm{G} \text { network) }\end{array}$ & $\begin{array}{l}2 \text { (in favor of the user } \\
\text { experience of other } \\
\text { prevalent forms of wireless } \\
\text { internet connection such as } \\
\text { WIFI and } 4 G \text { network) }\end{array}$ & 3 (Neutral) & $\begin{array}{c}4 \text { (in favor of the } \\
\text { user experience } \\
\text { of online platform } \\
\text { based on } 5 G \\
\text { network) }\end{array}$ & $\begin{array}{l}5 \text { (strongly in } \\
\text { favor of the } \\
\text { user experience } \\
\text { of online } \\
\text { platform based } \\
\text { on } 5 \mathrm{G} \text { network) } \\
\end{array}$ & $\begin{array}{c}\text { Mean } \\
\pm \text { Std. } \\
\text { Deviation }\end{array}$ \\
\hline $\begin{array}{l}\text { (17)Real-time interaction } \\
\text { based on } 5 \mathrm{G} \text { network }\end{array}$ & $4(8.3 \%)$ & $5(10.4 \%)$ & $17(35.4 \%)$ & $11(22.9 \%)$ & $11(22.9 \%)$ & $3.42 \pm 1.2$ \\
\hline $\begin{array}{l}\text { (18)Image quality based on } \\
5 G \text { network }\end{array}$ & $4(8.3 \%)$ & $3(6.3 \%)$ & $21(43.8 \%)$ & $9(18.8 \%)$ & $11(22.9 \%)$ & $3.42 \pm 1.16$ \\
\hline $\begin{array}{l}\text { (19)Voice clarity based on } \\
\text { 5G network }\end{array}$ & $3(6.3 \%)$ & $9(18.8 \%)$ & $21(43.8 \%)$ & $6(12.5 \%)$ & $9(18.8 \%)$ & $3.19 \pm 1.14$ \\
\hline $\begin{array}{l}\text { (20)Latency and stability of } \\
5 \mathrm{G} \text { network }\end{array}$ & $6(12.5 \%)$ & $11(22.9 \%)$ & $21(43.8 \%)$ & $5(10.4 \%)$ & $5(10.4 \%)$ & $2.83 \pm 1.12$ \\
\hline
\end{tabular}

The second part of the questionnaire consists of 5 answer options which contain two extreme poles and a neutral option connected with intermediate answer options. It refers to the comparison between the user experience of online platform based on $5 \mathrm{G}$ network and other prevalent forms of wireless internet connection such as WIFI and 4G network. The options start with "strongly in favor of the user experience of other prevalent forms of wireless internet connection such as WIFI and 4G network" at 1 point, "neutral" at 3 point, and "strongly in favor of the user experience of online platform based on 5 G network" at 5. 
As it is shown in the result, though online TBL is more challenging for medical students to adapt to, they are still more inclined to use the blended teaching model and they respond well to and have high enthusiasm in the blended teaching model, especially female medical students, furthermore $5 \mathrm{G}$ network can present high-definition image quality, improve voice clarity, and make real-time interaction more appealing. That indicates online TBL via $5 \mathrm{G}$ network can better improve students' enthusiasm and sense of participation and it is promising to enhance the students' learning experience. Independent study through high-quality MOOCs and literature before class and team-based learning contribute to cultivating students' teamwork spirit and independent learning ability.

The impact of gender on the scores of the questionnaire: As the gender may have an impact on the scores of the questionnaire, a binary logistic regression was used to analyze the impact of gender on the scores of the questionnaire. Expectations on the course will have an impact on students' professionalism, attitude towards learning (question 1, Table 3). As for this question, it shows that the number of male students who are inclined to the blended teaching model is 0.13 times as much as that of female students (95\% CI: 0.028 0.602, $\mathrm{p}=0.009)$. In other word, female students have higher expectations on the blended teaching model. Moreover, the impact of the course on the comprehensive abilities and advanced thinking are highly related to the knowledge and learning skills that is one of the students' competencies (question 10, Table 3). It shows that the number of male students who are inclined to the blended teaching model is only 0.163 times as much as that of female students, which indicates that both female and male students believe the blended teaching model is beneficial to improving their comprehensive abilities and advanced thinking. As for question $17-20$, it shows that there is no difference between male and female in terms of online platform preferences.

\section{Discussion}

As speculated earlier, the findings of this study show that medical students prefer traditional online teaching model in terms of adaptability. With regard to the relevant observational indicators of competency-oriented medical education involved in the questionnaire, quite a number of medical students believe that the new blended model can, to some extent, cultivate their professionalism, stimulate their motivation in learning and bring more fun to the study even though they are not in a physical classroom. Meanwhile, TBL cultivates students' preview and independent learning ability [11-12]. Team-based learning experience fosters their teamwork spirit [11-12]. The result of this study to some degree further confirm that Chinese government has implemented timely and correct strategies in response to the PHEIC, which extends higher medical education from school to home and accelerated the popularization of online education. It may be an inevitable trend for the development of medical education in the future.

Considering the nature of online courses, teachers can hardly monitor students' learning efficiency and test their real-time learning effectiveness; following are some advice to ensure the learning experience of online TBL for PHEIC:

1) Familiarize with the live streaming platform in advance and test it, and make precautionary plans for unstable network environment.

2) Promote the application of $5 G$ network in live streaming teaching and increase the bandwidth. The results of this study show that image quality, voice clarity, network speed and latency of 5G network are all better than other forms of wireless network connection.
3) In the process of teaching, course content can be divided into several fragments or small units, and some content-related interactions and tests can be presupposed.

4) With flipped classroom, students can study on their own first, find some common problems through exercises, tests and tasks, and then attend the live streaming to solve those problems.

5) The teacher ought to turn on the camera throughout the teaching process to maintain a sense of presence.

6) Avoid the online rush hours to ensure a stable live streaming during the pandemic.

7) Publish daily learning tasks at a fixed time to create a good online learning atmosphere, and check students' learning tasks in a timely fashion.

8) Offer learning support services, such as designating an excellent student as an assistant, managing class discipline, and collecting questions raised by students.

9) Organize live streaming classes and answer students' doubts to strengthen their sense of actually being in the class.

10) Drawing up a plan to promote high-quality MOOCs [13], "golden courses" and micro courses after the PHEIC.

Pandemic prevention requires joint efforts by higher medical education managers, teachers and students. Amid current pandemic, the administrative department of higher medical education and school administrators should take actions based on a long-term perspective, systematic thinking and top-level design. As teachers are the main body of the action of "keep medical schools running without suspending classes". On the one hand, teachers have to change their ideas to form a "student-centered" teaching concept. On the other hand, they ought to acquire more knowledge of online teaching. Apart from basic professional knowledge, ideological and political concept, benevolence to patients, contribution to society, as well as the preventive medicine should be integrated into online courses. All in all, it is necessary to raise medical student awareness of PHEIC during the pandemic, especially teach them about precautionary and preventive measures such as clinical diagnosis and treatment, isolation of patients and self-protection so that they can be competent in the future to handle PHEIC and give medical guidance to the masses.

We recognized some potential limitations in this study. 1) " $5+3$ " pattern is an innovative training pattern in China, thus students under " $5+3$ " pattern may not represent medical students all over the world. 2) Although the questionnaires we designed were based on the six core competences, it still needs further investigation and follow-up studies to verify its validity.

\section{Conclusion}

"Keep medical schools running without suspending classes" is China's crisis intervention strategy for higher medical education in response to COVID-19 outbreak. Before the COVID-19 outbreak, we have adopted a new blended teaching model via 5G network, which makes up for some deficiencies of the traditional online teaching methods. For instance, it can monitor students' learning efficiency and test their real-time learning effectiveness; $5 \mathrm{G}$ network meets the requirement of multiple user access in the online TBL and guarantees a more user-friendly experience of online learning. It is a more advanced online teaching and learning pattern for medical school and may be a more suitable method during PHEIC in the future. However, as the students can hardly quickly adapt to this new model, teachers should 
Table 3: Binary logistic regression.

\begin{tabular}{|c|c|c|c|c|c|c|}
\hline \multirow{2}{*}{ Question } & \multirow{2}{*}{ Inclination } & \multirow{2}{*}{ B } & \multirow{2}{*}{$\mathbf{P}$} & \multirow{2}{*}{$\operatorname{Exp}(B)$} & \multicolumn{2}{|c|}{$95 \% \mathrm{Cl}$} \\
\hline & & & & & Lower & Upper \\
\hline \multirow{3}{*}{$1^{*}$} & 1 & 0 & & & & \\
\hline & 2 & -1.012 & 0.201 & 0.364 & 0.077 & 1.716 \\
\hline & 3 & -2.041 & $0.009 *$ & 0.13 & 0.028 & 0.602 \\
\hline \multirow{3}{*}{2} & 1 & 0 & & & & \\
\hline & 2 & -1.076 & 0.159 & 0.341 & 0.076 & 1.522 \\
\hline & 3 & -1.058 & 0.131 & 0.347 & 0.088 & 1.371 \\
\hline \multirow{3}{*}{3} & 1 & 0 & & & & \\
\hline & 2 & -2.197 & 0.057 & 0.111 & 0.012 & 1.068 \\
\hline & 3 & -1.224 & 0.169 & 0.294 & 0.051 & 1.683 \\
\hline \multirow{3}{*}{4} & 1 & 0 & & & & \\
\hline & 2 & 0.799 & 0.24 & 2.222 & 0.587 & 8.41 \\
\hline & 3 & 0.329 & 0.68 & 1.389 & 0.292 & 6.608 \\
\hline \multirow{3}{*}{5} & 1 & 0 & & & & \\
\hline & 2 & -2.262 & 0.064 & 0.104 & 0.01 & 2.388 \\
\hline & 3 & -0.47 & 0.492 & 0.625 & 0.164 & 2.388 \\
\hline \multirow{3}{*}{6} & 1 & 0 & & & & \\
\hline & 2 & -1.386 & 0.317 & 0.25 & 0.017 & 3.77 \\
\hline & 3 & 0.054 & 0.951 & 1.056 & 0.188 & 5.926 \\
\hline \multirow{3}{*}{7} & 1 & 0 & & & & \\
\hline & 2 & -0.588 & 0.464 & $0-.556$ & 0.115 & 2.679 \\
\hline & 3 & -0.773 & 0.257 & 0.462 & 0.121 & 1.759 \\
\hline \multirow{3}{*}{8} & 1 & 0 & & & & \\
\hline & 2 & -1.322 & 0.211 & 0.267 & 0.034 & 2.116 \\
\hline & 3 & -0.47 & 0.525 & 0.625 & 0.147 & 2.659 \\
\hline \multirow{3}{*}{9} & 1 & 0 & & & & \\
\hline & 2 & -2.015 & 0.06 & 0.133 & 0.016 & 1.085 \\
\hline & 3 & -1.447 & 0.059 & 0.235 & 0.052 & 1.056 \\
\hline \multirow{3}{*}{$10^{*}$} & 1 & 0 & & & & \\
\hline & 2 & -1.792 & 0.138 & 0.167 & 0.016 & 1.777 \\
\hline & 3 & -1.817 & $0.036^{*}$ & 0.163 & 0.03 & 0.889 \\
\hline \multirow{3}{*}{11} & 1 & 0 & & & & \\
\hline & 2 & -1.658 & 0.172 & 0.19 & 0.018 & 2.061 \\
\hline & 3 & -1.609 & 0.066 & 0.2 & 0.036 & 1.11 \\
\hline \multirow{3}{*}{12} & 1 & 0 & & & & \\
\hline & 2 & -1.253 & 0.241 & $0 . .286$ & 0.035 & 2.322 \\
\hline & 3 & -0.754 & 0.297 & 0.471 & 0.114 & 1.942 \\
\hline \multirow{3}{*}{13} & 1 & 0 & & & & \\
\hline & 2 & -0.762 & 0.348 & 0.467 & 0.095 & 2.292 \\
\hline & 3 & -0.644 & 0.33 & 0.525 & 0.144 & 1.919 \\
\hline \multirow{3}{*}{14} & 1 & 0 & & & & \\
\hline & 2 & -0.916 & 0.214 & 0.4 & 0.094 & 1.699 \\
\hline & 3 & -0.868 & 0.224 & 0.42 & 0.104 & 1.702 \\
\hline
\end{tabular}

\begin{tabular}{|c|c|c|c|c|c|c|}
\hline \multirow{3}{*}{15} & 1 & 0 & & & & \\
\cline { 2 - 7 } & 2 & 0 & 1 & 1 & 0.214 & 4.674 \\
\cline { 2 - 7 } & 3 & -0.522 & 0.459 & 0.593 & 0.149 & 2.365 \\
\hline \multirow{4}{*}{16} & 1 & 0 & & & & \\
\cline { 2 - 7 } & 2 & -0.154 & 0.842 & 0.857 & 0.189 & 3.888 \\
\cline { 2 - 7 } & 3 & -0.442 & 0.534 & 0.643 & 0.16 & 2.585 \\
\hline \multirow{4}{*}{17} & 1 & 0 & & & & \\
\cline { 2 - 7 } & 2 & -1.299 & 0.135 & 0.273 & 0.05 & 1.502 \\
\hline \multirow{4}{*}{18} & 3 & -0.974 & 0.145 & 0.378 & 0.102 & 1.397 \\
\cline { 2 - 7 } & 1 & 0 & & & & \\
\hline \multirow{3}{*}{19} & 2 & -0.575 & 0.514 & 0.563 & 0.1 & 3.168 \\
\cline { 2 - 7 } & 3 & -0.693 & 0.514 & 0.5 & 0.144 & 1.735 \\
\cline { 2 - 7 } & 2 & 0 & & & & \\
\hline \multirow{3}{*}{20} & 3 & -1.179 & 0.121 & 0.308 & 0.069 & 1.363 \\
\hline & 1 & 0 & & & & \\
\hline & 2 & 0.452 & 0.493 & 1.571 & 0.432 & 5.714 \\
\hline & 3 & -0.752 & 0.357 & 0.471 & 0.095 & 2.337 \\
\hline
\end{tabular}

Question 1-16: 1: No inclination; 2: inclined to traditional online teaching model; 3: Inclined to blended teaching model.

Question 17-20: 1: No inclination; 2: Inclined to other prevalent forms of wireless internet connection such as WIFI and 4G network; 3: Inclined to the user experience of online platform based on $5 \mathrm{G}$ network. $* p<0.05$

change their ideas to form a "student-centered" teaching concept, acquire more knowledge of online teaching, and get fully prepared for online TBL before class to ensure a better study experience.

\section{Declarations}

\section{Ethical approval and consent to participate}

The study protocol was approved by the Ethics Committee of Fujian Provincial Hospital (No. K2020-04-41).

\section{Consent for publication}

Not applicable.

\section{Availability of data and materials}

All data generated or analysed during this study are included in this published article (and its supplementary information files).

\section{Competing interest}

The authors declare that they have no competing interests.

\section{Funding}

None

\section{Author's contribution}

- Conception and design: GC, WL and YC

- Administrative support: GC and JW

- Provision of study materials or patients: $\mathrm{HH}, \mathrm{WL}$ and YC

- Collection and assembly of data: WL, JL, LL, NW, LZ and LC 
- Data analysis and interpretation: WL, SS and JW

- Manuscript writing: WL, YC and SS

- Final approval of manuscript: All authors

\section{Acknowledgements}

Not applicable

\section{References}

1. World Health Organization (2020) Statement on the meeting of the International Health Regulations (2005) Emergency Committee regarding the outbreak of novel coronavirus (2019-nCoV). WHO, Geneva, Switzerland.

2. Eurosurveillance Editorial Team (2020) Note from the editors: World Health Organization declares novel coronavirus (2019-nCoV) sixth public health emergency of international concern. Euro Surveill 25 : 200131e.

3. Rio CD, Malani PN (2020) 2019 Novel Coronavirus-Important Information for Clinicians. JAMA 323: 1039-1040.

4. Nishiura H, Jung S-M, Linton NM, Kinoshita R, Yang Y, et al. (2020) The Extent of Transmission of Novel Coronavirus in Wuhan, China, 2020. J Clin Med 9: 330.

5. Wu F, Zhao S, Yu B, Chen Y-M, Wang W, et al. (2020) A new coronavirus associated with human respiratory disease in China. Nature 579: 265-269.

6. Frenk J, Chen L, Bhutta ZA, Cohen J, Crisp N, et al. (2010) Health professionals for a new century: transforming education to strengthen health systems in an interdependent world. Lancet 376 : 1923-1958.
7. Jin H, Hu YY, Song L (2017) Technology promotes education innovation: an analysis of the NMC horizon report: 2017 higher education edition. Journal of Distance Education: 3-8.

8. Wang GH, Yu SY, Huang HF, et al. (2015) An analysis of the current research status of blended learning in China. Distance Education in China 25-31.

9. Rajalingam P, Rotgans JI, Zary N, Ferenczi MA, Gagnon P, et al. (2018) Implementation of team-based learning on a large scale: Three factors to keep in mind. Med Teach 40: 582-588.

10. Wang S, Fu X, Liu Z, Wang B, Tang Y, et al. (2018) General Practitioner Education Reform in China: Most Undergraduate Medical Students do not Choose General Practitioner as a Career Under the $5+3$ Model. Health Prof Educ 4: 127-132.

11. Wai AK, Lam VS, Ng ZL, Pang MT, Tsang VW, et al. (2020) Exploring the role of simulation to foster interprofessional teamwork among medical and nursing students: A mixed-method pilot investigation in Hong Kong. J Interprof Care 1-9.

12. Hunger J, Schumann H (2020) How to achieve quality assurance, shared ethics and efficient teambuilding? Lessons learned from interprofessional collaboration during the COVID-19 pandemic. GMS J Med Educ 37: Doc 79.

13. Alturkistani A, Lam C, Foley K, Stenfors T, Blum ER, et al. (2020) Massive Open Online Course Evaluation Methods: Systematic Review. J Med Internet Res 22: e13851. 